\title{
Papers of \\ G. Cross, Y. Kubota, \\ J.L. Mawhin, M. Morayne, \\ W.F. Pfeffer and W.-C. Yang, \\ and C.A. Rogers
}

Papers delivered at the conference by G. Cross (U. Waterloo), Y. Kubota (Ibaraki U.), J.L. Mawhin (U. Louvain-la-neuve), M. Morayne (U. Wroclaw), W.-C. Yang (U. California, Davis), and C.A. Rogers (University College London) have not been included in this volume. The references are:

1. J. Cichon, M. Morayne, J. Pawlikowski, Decomposing Baire functions, Real Analysis Exchange 14 (1988-89) 16-19.

2. G. Cross, Generalized integrals as limits of Riemann-like sums, Real Analysis Exchange 13 (1987-88) 390-403.

3. Y. Kubota, Extension of the Denjoy integral, not yet published.

4. J.L. Mawhin, Applications of multiple generalised Riemann integrals, not yet published.

5. W.F. Pfeffer and W.-C. Yang, A multidimensional integral and its extensions, to appear in Real Analysis Exchange.

6. C.A. Rogers, Dimension prints, Mathematica 35 (1988) 1-27. 